\title{
Sustainable Humanitarian Supply Chain Management - Exploring New Theory
}

\author{
Nathan Kunz, ${ }^{a, *}$ and Stefan Gold ${ }^{b}$ \\ ${ }^{\text {a }}$ Coggin College of Business, University of North Florida, Jacksonville, FL, USA \\ ${ }^{\mathrm{b}}$ Nottingham University Business School, University of Nottingham, Nottingham, UK
}

\begin{abstract}
Disaster response operations aim at helping as many victims as possible in the shortest time, with limited consideration of the socio-economic context. During the disaster rehabilitation phase, the perspective needs to broaden and comprehensively take into account the local environment. We propose a framework of sustainable humanitarian supply chain management (SCM) that facilitates such comprehensive performance. We conceptualize the framework by combining literature from the fields of sustainable and humanitarian SCM. We test the framework through an analytic induction process by means of multiple case studies of four relief organisations. Our framework suggests that supply chain design needs to be aligned not only to relief organisations' enablers, but also to the population's long-term requirements as well as any socio-economic and governmental contingency factors. A good fit between these dimensions leads to sustainable performance. The framework provides an instrument for relief organisations to achieve sustainable performance in the disaster rehabilitation phase.
\end{abstract}

Keywords: supply chain management, humanitarian logistics, sustainability, disaster rehabilitation, government, case studies

This is the Author's Original Manuscript of an article published by Taylor \& Francis in International Journal of Logistics Research and Applications on 02 November 2015, available online: http://wwww.tandfonline.com/10.1080/13675567.2015.1103845.

To cite this article:

Nathan Kunz \& Stefan Gold (2015): Sustainable humanitarian supply chain management Exploring new theory, International Journal of Logistics Research and Applications, DOI: 10.1080/13675567.2015.1103845

To link to this article: http://dx.doi.org/10.1080/13675567.2015.1103845

*Corresponding author: nathan.kunz@unf.edu 


\section{Introduction}

Events such as a fire or an accident require immediate and effective action for saving human lives, without too much cogitation about possible side effects of rescue operations. By analogy, during the immediate response phase of a disaster, humanitarian disaster relief operations aim at saving as many victims as possible in the shortest possible time, with limited consideration of the context of the operation area. During the disaster rehabilitation phase, however, the focus changes to helping the population regain a pattern of life as close as possible to their pre-disaster status, or even better than before. In order to achieve this, the perspective needs to broaden and comprehensively take into account the specific local environment of the operation area for strengthening entire geographical entities. Working with local supplier networks, building and disseminating capacities, and regionally sourcing workers, raw materials and products are examples of supply chain management decisions that may all contribute to a more sustainable disaster rehabilitation phase.

Despite calls from research and practice for increasing sustainability of disaster rehabilitation operations (e.g., Van Wassenhove and Pedraza Martinez 2012; Maon, Lindgreen, and Vanhamme 2009), theory on sustainable humanitarian supply chain management (SCM) is scarce. Haavisto and Kovács (2014) analysed how relief organizations address sustainability by analysing 11 activity reports of relief organizations. Our paper complements this study by conceptualizing a framework for sustainable humanitarian SCM, thus holding humanitarian supply chain operations in the disaster rehabilitation phase explicitly accountable for their social, environmental, and economic impact. We do this by combining existing theory on sustainable SCM with theory on humanitarian SCM. In this way, we aim at laying the foundation for future humanitarian logistics and SCM research to increasingly look beyond the narrow confines of operational and economic performance objectives and to consider multi-dimensional sustainability performance. This helps relief 
organisations and policy-makers taking a distinctly comprehensive and long-term perspective when managing humanitarian disaster rehabilitation projects. We use empirical data from multiple case studies to test the framework and to understand how external contingency factors are affecting the sustainability of disaster rehabilitation. We define external contingency factors as factors that are exogenous to the relief organisation-beneficiary relationship, are specific to the context in which the organisation operates, and have a strong impact on the relief operation. External contingency factors are similar to what Haavisto and Kovács (2014) name the 'organisational context', and what Kunz and Reiner (2012) call 'situational factors'.

This paper focuses on two of the four types of factors proposed by Kunz and Reiner (2012) that have the strongest impact in the disaster rehabilitation phase, namely government contingency factors and socio-economic contingency factors (i.e., the society and economic context in a country). It specifically looks at the rehabilitation phase of complex disasters in developing countries. While disaster mitigation, preparedness and response are all important phases in disaster management, our paper focuses on the rehabilitation phase, which has been studied far less in academic literature. Complex disasters are characterised by a combination of causes, and often result from both man-made and natural causes (Starr and Van Wassenhove 2014). We focus on developing countries because they appear to be less resilient to disasters than industrialised economies.

This paper addresses the following research questions: (1) How can sustainable SCM and humanitarian SCM be combined into an integrated framework? (2) How are external contingency factors to be taken into account for increasing the sustainability of disaster rehabilitation operations?

The paper is structured as follows. Based on the literature streams of sustainable SCM and humanitarian SCM, we develop the proposed framework of sustainable humanitarian 
SCM and derive research propositions to be tested. After describing the methodology used for collecting and analysing data in the frame of a multiple case study design, we test our propositions with evidence from our case study data, and then discuss the findings. The paper concludes with implications for research and practice, and suggests avenues for future research.

\section{Literature Review}

Since we apply theory of sustainable SCM to the field of humanitarian operations in the rehabilitation phase, we start by reviewing the most relevant literature concerning these two streams of research. The subsequent section then condenses the building blocks of sustainable and humanitarian SCM into a framework of sustainable humanitarian SCM.

\subsection{Sustainable Supply Chain Management}

The research field of sustainable SCM refers to an overarching concept of how to analyse and manage interlinked business activities for the overall benefit of all chain members and the society where the supply chain operates, while respecting the ecological carrying capacity. Thereby, the concept of sustainable SCM builds on the concept of sustainable development, defined by the Brundtland Commission as 'a development that meets the needs of the present without compromising the ability of future generations to meet their own needs' (Brundtland 1987, p.16). We adopt the prominent definition of sustainable SCM offered by Seuring and Müller, who consider sustainable SCM as

\footnotetext{
'The management of material, information and capital flows as well as cooperation among companies along the supply chain while taking goals from all three dimensions of sustainable development, i.e., economic, environmental and social, into account which are derived from customer and stakeholder requirements.' (Seuring and Müller 2008, p.1700).
} 
This definition explicitly builds on the 'triple bottom line' (TBL) approach that dynamically integrates the economic, ecological and social sustainability dimensions (Dyllick and Hockerts 2002).

\subsubsection{Sustainable Supply Chain Management and the Triple Jump Model}

Sustainable SCM has been repeatedly conceptualised in form of a triple jump model (enablers-design-performance) (see Figure 1) whereby sustainable supply chain enablers translate into a specific supply chain design which in turn facilitates TBL performance (e.g., Gold, Hahn, and Seuring 2013, referring to Pagell and Wu 2009). This model will be integrated into our framework, and is described in more detail below.

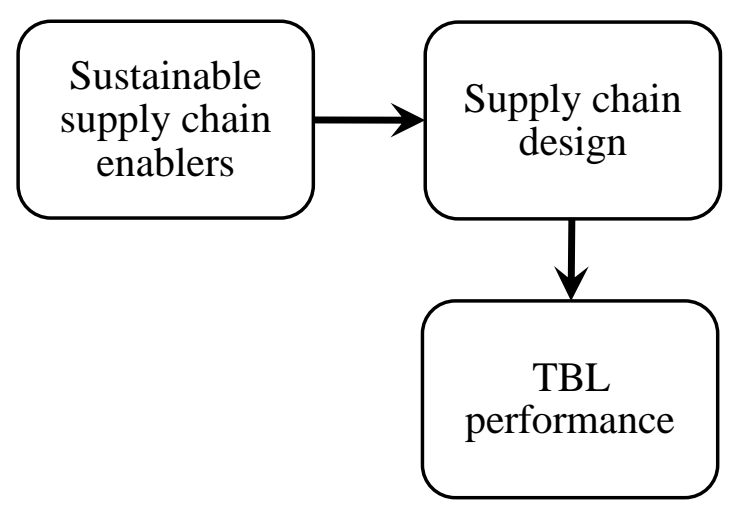

Figure 1. Triple Jump Model of Sustainable Supply Chain Management (adapted from Gold et al., 2013)

\subsubsection{Sustainable Supply Chain Enablers}

The first building block, the sustainable supply chain enablers, comprises all attitudes, policies and capabilities that facilitate the set-up of a supply chain design appropriate for pursuing and achieving multi-dimensional sustainability performance. Sustainable supply chain enablers may refer to the individual level or to the corporate level (cf. Gold, Hahn, and Seuring 2013). On the individual level, the commitment of top management as well as that of all employees is indispensable for shaping strategic orientation and for consistently translating 
this orientation into day-to-day behaviour aligned to sustainability goals (Cantor et al. 2013; Schrettle et al. 2014; Abbasi and Nilsson 2012). On the corporate level, the organisation needs to incentivise employees for reaching sustainability goals through appropriate reward systems (Pagell and Wu 2009) and to foster organisational absorptive capacity regarding sustainability-relevant external information (Daghfous 2007).

\subsubsection{Supply Chain Design}

The second building block refers to the characteristics of supply chain design, hence the challenge of identifying, developing, and managing an optimal constellation of (supply chain) actors and of setting up supply chain processes for delivering sustainable performance to consumers and other stakeholders. Sustainable supply chains feature particularly high levels of (process, product, and actor related) monitoring, coordination, and collaboration throughout the entire chain (Gold, Seuring, and Beske 2010; Gimenez and Tachizawa 2012), relying on information transparency, enhanced communication, and trust (Han and Dong 2015; van Hoof and Thiell 2014). It is usually the role of the focal company, i.e. the company that governs the supply chain, to extend sustainability towards its suppliers through direct (e.g., training, education, investments) and indirect supplier development (e.g., supplier evaluation, auditing) (Yawar and Seuring 2015). Collaboration may extend to governmental and non-governmental organisations as chain members (Pagell and Wu 2009), especially in a developing country context where (multinational) companies often lack knowledge and legitimacy in local communities and are confronted with turbulent business environments and institutional voids (Silvestre 2015). By collaborating with civil society and governmental organisations, institutional ambiguity may be reduced and local legitimacy developed (Hahn and Gold 2014). In this way, organisations that used to be considered as external stakeholders are now actively included in the novel supply chain design, thus leveraging their resources and capabilities for the benefit of the chain. 


\subsubsection{Triple Bottom Line Performance}

While traditional supply chain performance is directed towards financial and operational indicators, sustainable supply chains reach for TBL performance (Gimenez, Sierra, and Rodon 2012). They thus face the challenge of dynamically balancing the various sustainability dimensions (Wu and Pagell 2011). For the purpose of this research, we conceive social and ecological performance as equal to economic performance, while considering and assessing each performance category individually.

\subsection{Humanitarian Supply Chain Management in Disaster Rehabilitation}

After the Asian Tsunami in 2004, humanitarian logistics was acknowledged publicly to play a central role in effective disaster relief (Thomas and Kopczak 2005), which led to an increasing interest in this area for both relief practitioners and academic researchers (Kovács and Spens 2007). From an initially strictly logistics perspective, the field has progressively evolved towards a SCM approach (Thomas and Kopczak 2005). This involves not only material flows but also information and financial flows, and tasks such as procurement, coordination, and customs clearance. According to Van Wassenhove (2006), effective humanitarian SCM must be able to respond as quickly as possible to multiple interventions, despite always facing high levels of uncertainty. Humanitarian SCM and logistics is important because it directly affects the success of the humanitarian aid effort (Beamon and Kotleba 2006).

\subsubsection{Typologies of Disasters}

Disasters are categorised into three groups: man-made, natural disasters and complex disasters (Van Wassenhove 2006). Our paper focuses on complex disasters, often resulting from both man-made and natural causes, that are generally responded to by humanitarian organisations that already have a local presence through long term developmental aid projects (Starr and 
Van Wassenhove 2014). According to Starr and Van Wassenhove (2014), such disasters happen more frequently and so deserve more research.

Disaster management is categorised into different phases, with several classifications having been proposed thus far (e.g., Kovács and Spens 2007; Van Wassenhove 2006; Altay and Green 2006). In this paper, we will use the four stage framework proposed by Van Wassenhove (2006), consisting of mitigation (reducing the potential impact of a disaster), preparedness (preparing in order to improve the response in case of disaster), response (reaching and helping victims in the immediate aftermath of a disaster) and rehabilitation (long-term rebuilding of the country's infrastructure). Some authors also use the term 'reconstruction' when referring to this phase (see e.g., Heaslip and Barber 2014; Kovács and Spens 2011).

The boundaries between the different phases are not always clear, and overlaps between subsequent phases are often found. At the end of the disaster management cycle, the rehabilitation phase then fades to development aid, which aims at building local capacity in vulnerable areas. The transition from relief to development aid is particularly observed in complex disasters, for which Starr and Van Wassenhove (2014, p.934) state that 'the dividing line between disasters and development becomes thinner since disaster relief constitutes an opportunity to start work on development issues that will follow the end of the disaster relief phase.'

This transition from relief to development aid is often difficult, and requires what is called Linking Relief, Rehabilitation and Development (LRRD). This concept originated in the 1980s when researchers and practitioners identified a gap between relief, rehabilitation and development activities (Ramet 2012). This gap is caused by a lack of coordination between relief and development sector or inadequate exit strategies from relief agency (Lai et al. 2015). There is a consensus that relief programs should be designed in a way that they 
facilitate the transition from relief to development (Besiou, Stapleton, and Van Wassenhove 2011). This is however not always the case in reality. Funding conditionality is a barrier to effective LRRD, as some donors tie funding to a specific phase of a disaster (i.e., earmarking). This can prevent relief agencies to implement more sustainable, long-term projects that would have a positive impact in the development phase (Christoplos 2006).

In this paper, we will concentrate on the rehabilitation phase, which has been the least studied of all four phases so far in academic literature (See e.g., Altay and Green 2006; Kunz and Reiner 2012; Leiras et al. 2014). It may be noted that actions taken in one phase can positively or negatively affect the ability to achieve the objectives of the next phase. In humanitarian supply chains, it often happens that actions carried out in the disaster response phase compromise the ability of the system to recover during the rehabilitation phase (Day et al. 2012).

\subsubsection{Sustainability of the Rehabilitation Phase}

In the rehabilitation phase of a complex disaster, sustainable humanitarian SCM should concentrate on rebuilding structures that will increase food security (i.e., ensuring that the entire population has access to sufficient and healthy food), such as rebuilding roads to allow the population to reach markets, clearing agricultural fields of landmines, or developing small businesses thereby contributing to enhanced food production and distribution (McLachlin, Larson, and Khan 2009; Altay and Green 2006). Such activities decrease the vulnerability of populations and their reliance on relief aid in the future.

Local procurement of goods and services by relief organisations has positive effects on the economic development of the affected country, provided that they are available in sufficient quantity and quality on the market (Jahre and Spens 2007; Maxwell 2007; Perry 2007; Kovács, Matopoulos, and Hayes 2010; Pazirandeh 2011; Herlin and Pazirandeh 2012). Moreover, local procurement ensures that the procured items and solutions satisfy any 
cultural and regional requirements (Kovács, Matopoulos, and Hayes 2010; Perry 2007; Long and Wood 1995). Finally, local procurement leads to lower costs and requires shorter lead times (Balcik and Beamon 2008; Balcik et al. 2010; Lentz, Passarelli, and Barrett 2013). Local procurement can however involve risks of corruption (Schultz and Søreide 2008) and ethical conflicts, as ethical procurement standards required by large donors are not always applicable when sourcing from small local suppliers. Donors therefore increasingly intervene in the supply chain of some commodities such as vaccines, reshaping market structures and tying specific requirements to their donations (Herlin and Pazirandeh 2012). Another way to increase the sustainability of humanitarian SCM is to involve local partners in the rehabilitation effort. It is thus possible to benefit from their 'social capital' (Day et al. 2012), consisting of, for example, deep knowledge of the local environment or their existing relationships (Oloruntoba and Gray 2006; Perry 2007). Similarly, McLachlin et al. (2009) found that working with local partners provides many advantages as they have stronger connections with local communities and authorities, and a better knowledge of the local culture and values.

In some activities, such as construction, the involvement of local partners ensures that local building codes are followed (Kovács, Matopoulos, and Hayes 2010) or that adequate sites are selected for locating strategic inventories (Oloruntoba and Gray 2006). However, despite these multiple recommendations from literature, Sheppard et al. (2013) found that the contribution of local population and partners in humanitarian SCM has been underutilised until now.

The literature on humanitarian SCM in the rehabilitation phase presented in this section demonstrates the importance of combining organizations' enablers with beneficiaries' requirements for achieving higher performance. In this paper, we therefore conceptualise humanitarian SCM performance as flowing from a strategic reconciliation between relief 
organisations' enablers (resources, capabilities and commitment) and beneficiaries' requirements, such as survivability, speed of answer, or safety (see Kunz and Reiner 2012; based on Slack and Lewis 2002), via an optimal supply chain design, as presented in Figure 2.

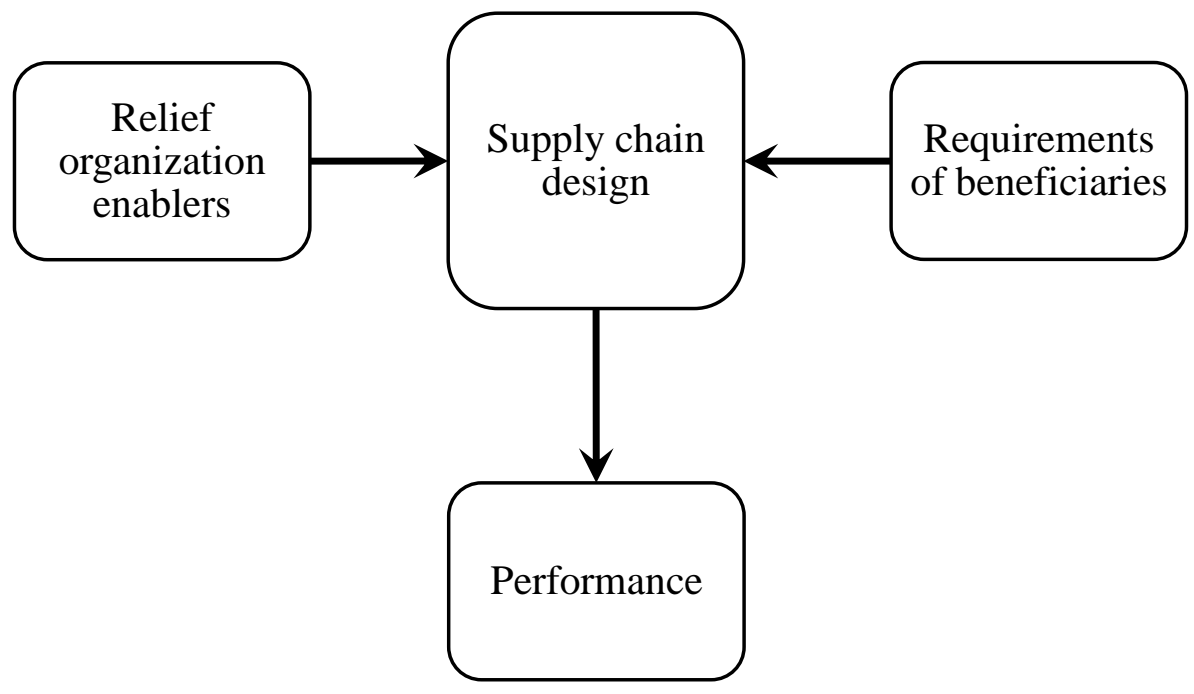

Figure 2. Framework of Humanitarian Supply Chain Management (adapted from Kunz and Reiner, 2012)

This supply chain design is similar to the 'supply chain strategy' recognized as a critical success factor for humanitarian supply chain management by Pettit and Beresford (2009); in a humanitarian aid context, value for beneficiaries is generated by delivering the appropriate products to the right people at the right time.

\section{Framework of sustainable humanitarian supply chain management}

Combining the literature streams and models of sustainable SCM (Figure 1) and humanitarian SCM (Figure 2), we develop a framework of sustainable humanitarian SCM for the rehabilitation phase of disasters, as shown in Figure 3. 


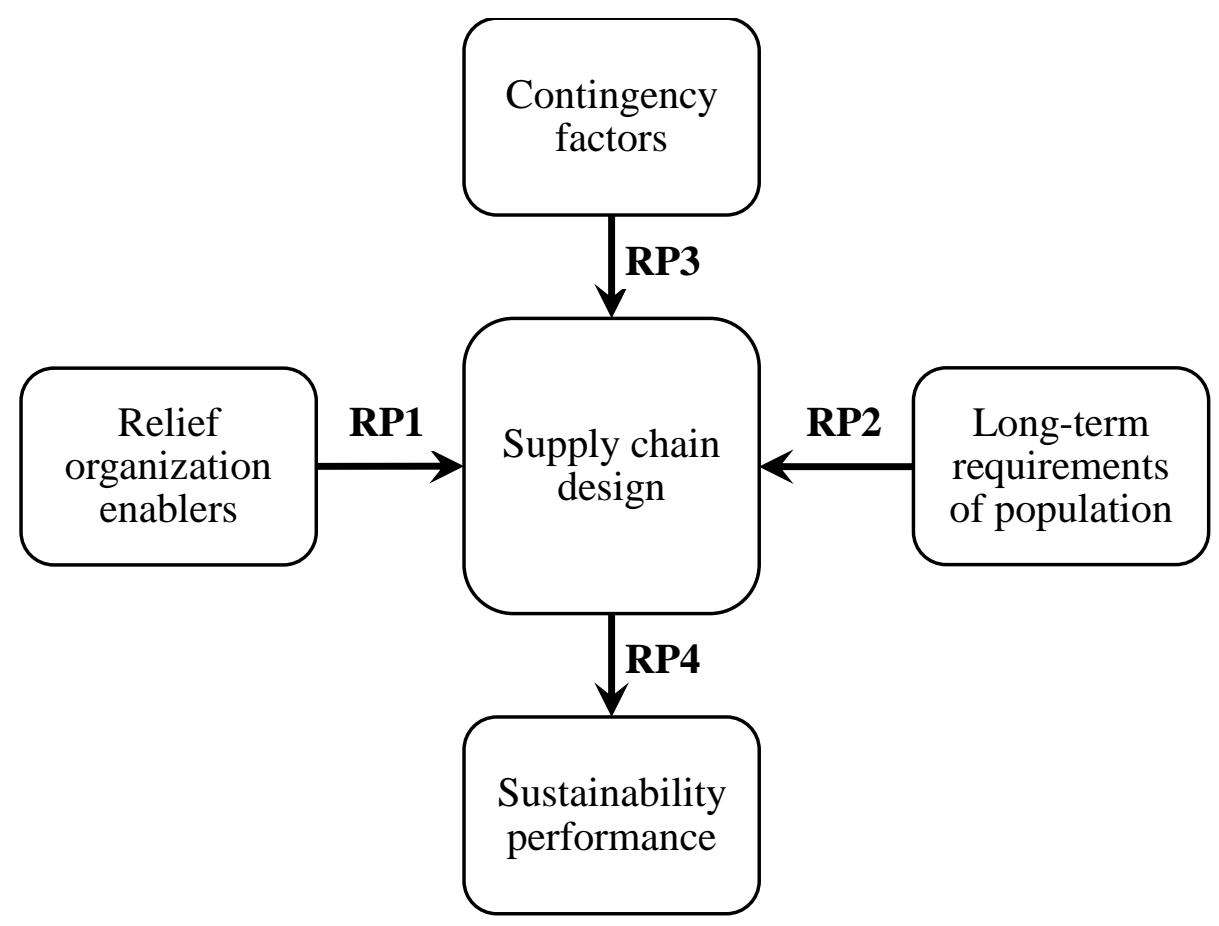

Figure 3. Framework of Sustainable Humanitarian Supply Chain Management (RP1 - RP4 are the research propositions testing each link)

The specific operational context of humanitarian supply chains suggests that supply chain designs need to be aligned not only to relief organisations' enablers, but also to the long-term requirements of recipients and the entire population as well as socio-economic and governmental contingency factors. Similarly to Haavisto and Kovács (2014), our framework suggests that a good fit between relief organisations' enablers, the population's long-term requirements, and contingency factors will lead to sustainable performance. This hypothesis will be tested through the research propositions RP1 to RP4 that are developed below. We conceive the fit between the different dimensions as a specific adaptation of the organisation's supply chain design to the population's requirements and contingency factors, as described by contingency theory (Lawrence and Lorsch 1967). According to this theory, an organisation adapts its structure to fit contingency factors, with the aim of achieving high performance.

Contingency theory suggests that there is no single ideal structure that fits all organisations, but that the optimal structure is rather contingent upon several contextual factors and is the result of an adaptation process. The contingency theory focuses on three 
groups of variables (Sousa and Voss 2008): the context variables which are beyond the control of the organisation (our contingency factors), the response variables which include the organisation's actions to respond to the context variables (our supply chain design), and the performance variables which are the measures allowing the assessment of the fit between contextual and response variables (our sustainable performance on the TBL). The suitability of using contingency theory for our framework is backed by its frequent application in the field of SCM (e.g., Flynn, Huo, and Zhao 2010; Wagner and Bode 2008; Huang, Yen, and Liu 2014). This theory has also been applied by Haavisto and Kovács (2014) in the context of sustainability in humanitarian SCM.

We conceive performance of humanitarian supply chains in the direct response phase of a disaster as a multi-faceted construct composed by effectiveness and efficiency. On the operational side, supply chain effectiveness indicates the fit of the relief organisation enablers with beneficiary requirements, such as survivability, reaction speed, flexibility and serviceableness (quality) of products and services. Supply chain efficiency is measured by the quantity of services and products provided within a given budget (Kunz and Reiner 2012). Sustainability performance of humanitarian supply chains in the rehabilitation phase embraces supply chain effectiveness and efficiency maintained over the long-term and collateral performance for the population in the disaster zone (directly affected and adjacent population). In this respect, supply chains ideally aim for generating positive social, environmental and economic impacts on the affected and non-affected population, i.e. they aim to create value on the TBL. Considering all three sustainability dimensions, humanitarian SCM's ultimate purpose is the long-term development of resources and capabilities of affected regions and their populations, thus strengthening disaster resilience among local communities (cf. Gaillard 2007). 
In our framework, enablers of a relief organisation are resources (financial, human resources, physical network), capabilities (routines, established processes, knowledge, experience, skills) as well as the commitment of each employee and the organisation as a whole. These assets are indispensable in aiming for performance at the TBL in the disaster rehabilitation phase when situation-adapted supply chain designs have to be found that rely on the relief organisation's absorptive capacity of relevant external information and knowledge (cf. Daghfous 2007). Key enablers of relief organisations are proactive and highly-motivated staff members, which store the experience, drive the mission, and create the organisational culture. As another significant enabler of humanitarian supply chains, financial resources are collected through private donations or from institutional funding. Finances and staff are obviously linked, as the number and experience level of staff depends on the financial strength of a relief organisation. Financial resources also allow a relief organisation to acquire more capabilities, by hiring specialised staff or consultants who bring additional skills and experience into the organisation. These considerations lead to the first research proposition:

RP1: The more extensive a relief organisation's resources, capabilities and commitment (enablers) are, the greater the capacity of that organisation to identify and establish an adequate supply chain design. Thereby, supply chain design may be conceived as adequate if it accommodates both contingency factors and the population's long-term requirements.

In our framework, the long-term requirements of the population include the needs of both the people affected by the disaster and those who are not directly affected (the adjacent population). These requirements are generally not the same and vary over time. Indeed, delivering free food relief aid to the affected population is certainly initially positive for the beneficiaries. In the long-term, however, it creates a negative impact on another part of the population, for example the farmers who cannot sell their produce anymore. It is therefore extremely important to take into consideration the requirements of the entire population when 
framing sustainable performance of humanitarian supply chains. This holds true not only for socio-economic impacts, but also for the long-term ecological impacts of rehabilitation activities. For example, providing free food aid to developing countries not only has a negative economic impact on local producers, but also negatively impacts on the environment by generating carbon emissions Against this background, we formulate the second research proposition:

RP2: The more comprehensively the population's long-term requirements are taken into account (in terms of population groups and sustainability dimensions), the more effective a relief organisation has to leverage its enablers in order to identify and establish an adequate supply chain design. Thereby, supply chain design may be conceived as adequate if it accommodates these long-term requirements with (governmental and socioeconomic) contingency factors.

In our model, we limit contingency factors to governmental factors and socio-economic factors. The importance of these factors is confirmed by Pettit and Beresford (2009) who recognize that it 'is almost certain that the political and economic environments in which a crisis occurs will influence the strategic planning of aid agencies' (Pettit and Beresford 2009, p.455). We define governmental factors as those factors which are imposed on relief operations by the highest authority in a given territory. This may be a national or local government, or any other entity which holds ultimate power in an area, be it legitimately (e.g., traditional figure of authority) or otherwise (e.g., armed rebel group). This highest authority, for which we use the word 'government', sets a number of laws and rules aimed at regulating economic activity as well as humanitarian aid. The government plays the role of the gatekeeper who decides which products can enter the country, by setting tariff or non-tariff import barriers and by regulating the activities of relief organisations. This role is particularly understandable when the disaster affected zone is confronted with a convergence of selfinitiated organisations (Day et al. 2012) and unsolicited donations (Holguín-Veras et al. 2012) 
which disturb humanitarian supply chains by creating unnecessary bottlenecks. In other cases, governments may restrict humanitarian supply chains for politically motivated reasons (Pettit and Beresford 2005; Seekins 2009; Pettit and Beresford 2009). Socio-economic contingency factors are, for example, the type of (market) economy prevailing in a country, the availability and quality of local suppliers or the presence of well-educated local staff. Factors such as culture, religion, or traditions are other important socio-economic contingency factors (Gaillard 2007; Rodon, Maria Serrano, and Gimenez 2012). The influence of contingency factors on sustainable humanitarian supply chain management is specified by the third research proposition:

RP3: The more cooperative governmental bodies are and/or the more resource-rich the socio-economic context is, the easier it is for relief organisations to leverage their enablers in order to identify and establish an adequate supply chain design. Thereby, supply chain design may be conceived as adequate if it accommodates these (governmental and socio-economic) contingency factors with the population's long-term requirements.

Humanitarian supply chain managers have to achieve a strategic reconciliation between the enablers of their relief organisation and the long-term requirements of the population, while still considering governmental and socio-economic contingency factors. This fit is operationalised in the optimal supply chain design, which leads to sustainable TBL performance of operations in the rehabilitation phase. Due to frequent changes in the environment (i.e., contingency factors) and in inter-organisational structures, humanitarian supply chains are dynamic by nature (Day et al. 2012). This requires relief organisations to regularly adapt their supply chain designs in order to maintain a fit with the population's changing requirements and contingency factors and so to attain (sustainable) performance in accordance with the contingency theory. Sustainable performance can, for example, be achieved when high levels of supply chain collaboration and coordination build up a 
'collaborative capacity' in the operational region (cf. e.g., Vachon and Klassen 2008) thus furthering learning and innovation (Silvestre 2015). Monitoring and controlling supply chains as well as developing suppliers by enhancing their resources and capabilities (cf. Gimenez and Tachizawa 2012) may be considered other central tasks of relief organisations aiming at sustainability performance. We condense the considerations above into the fourth research proposition:

RP4: The more effective supply chain design accommodates the relief organisation's enablers with the population's long-term requirements under consideration of contingency factors, the higher is the sustainability of performance. Thereby, the sustainability of performance may be conceived as value created on the economic, ecological and social dimension.

\section{Methodology}

\subsection{Selection of Method}

Due to the early stage of theory-building and a general dearth of empirical data in the field, no doubt linked to the great challenge of collecting primary data in a post-disaster developing country context, we used a case study research approach. Case study research designs are particularly well-suited for exploring under-theorised topics as they enable researchers to modify constructs, variables, and inter-relationships (Voss, Tsikriktsis, and Frohlich 2002). Furthermore, the case study approach is also particularly useful for analysing highly complex subjects within their specific contexts (Yin 2009), as is the case when analysing humanitarian supply chains in developing countries. Case study research is ideally fitted for answering 'why', 'what' and 'how' questions (Voss, Tsikriktsis, and Frohlich 2002), hence the type of questions that drive our research. 


\subsection{Sampling}

One case organisation with which we had conducted previous research on another topic was a 'revelatory case' (Yin 2009) that pointed to the importance of considering sustainability when analysing humanitarian supply chains in the rehabilitation phase; therefore we decided to extend the study to three other organisations, thus adopting the research design of a multiple case study. Multiple cases allow for the application of replication logic by repeatedly approaching the subject under investigation and checking the inferences derived from one case against the empirical evidence of the other cases, thus eventually distilling patterns of explanation (Yin 2009).

In order to select cases that would offer different characteristics, we applied a polar type sampling approach (Eisenhardt 1989). As differentiating factors, we chose age of the program and size of the organisation. We expect large organisations to have more developed procedures and resources for adapting their supply chains to the contingency factors than smaller organisations. Similarly, we anticipate organisations with a longer presence in a country to have a better knowledge of that country and its contingency factors.

In order to ensure that the phenomenon under study would be 'transparently observable' (Eisenhardt 1989), we conducted a content analysis of the publicly available secondary data (activity reports, newsletters, etc.) of a set of six pre-selected polar type relief organisations operating in our focus country, Chad. In order to allow comparability of data for the cross case analysis (Eisenhardt 1989), we decided to focus on relief organisations headquartered in Europe, with an ongoing field operation in Chad, and affected by substantial governmental and socio-economic contingencies, while differentiating themselves by program maturity and organisation size. This sampling process was conducted independently by 12 research assistants based on more than 10 documents published by each organisation. 
This theoretical sampling mechanism increases the external validity of our findings (Yin 2009).

Chad was selected as our focus country because it is in the rehabilitation phase of a complex disaster, and is therefore representative of the setting on which we focus in this paper. Chad has been involved in multiple wars since 1960, and suffers from regular droughts and epidemic outbreaks (CIA 2014). Numerous relief organisations are active in this country, working in the rehabilitation phases of these different crises. With a Gross National Income (GNI) per capita of 1020 USD in 2013, Chad is considered as a 'low income developing country' by the International Monetary Fund (IMF 2014). We focused our study on this country as we were informed about the relatively strong impact of governmental and socioeconomic contingency factors on humanitarian supply chains through an initial research project performed with an organisation working in this country.

Table 1 presents the four case organisations of our sample, and it can be seen that the Chad-based programs of the four differ in terms of age and size, and therefore fill different theoretical categories (Eisenhardt 1989). For confidentiality reasons, and due to the sensitivity of the topic (especially concerning questions related to governmental contingency factors), we offered the participants anonymity. 
Table 1. Key figures of the selected case organisations.

\begin{tabular}{l|c|c|c|c} 
& Org. A & Org. B & Org. C & Org. D \\
\hline Number of programs (countries of activity) & 3 & 80 & 20 & 43 \\
Yearly budget, in million USD & 2 & $>500$ & 160 & 150 \\
Government funding & $55 \%$ & $92 \%$ & $25 \%$ & $35 \%$ \\
Private and other donations & $45 \%$ & $8 \%$ & $75 \%$ & $65 \%$ \\
Number of international staff worldwide & 15 & 2,000 & 550 & 300 \\
Number of national staff worldwide & 12 & 10,000 & 3,700 & 1,700 \\
Sector & Mine clearance & $\begin{array}{c}\text { Assistance to } \\
\text { victims of war }\end{array}$ & Medical & Medical \\
Type of aid & Relief & Relief & Relief & Relief \& \\
Advocacy/Non-Advocacy & Don-Advocacy & Advocacy & Advocacy & Non-Advocacy \\
Faith based/Secular & Secular & Secular & Secular & Secular \\
\hline & & General & Medical & Medical \\
Type of imported goods & Equipment & supplies \& & supplies \& & supplies \& \\
Equipment
\end{tabular}

We define the unit of analysis of our multiple case studies as the program of an organisation in a country. Summing up the number of programs of all four organisations gives a total of 146 programs from which we collected data, while focusing our analysis on the Chad-related programs of the four case study organisations, complemented by programs in other developing countries in the rehabilitation of complex disasters (31 country programs were looked at).

\subsection{Data Collection}

The data collection was conducted in two steps. Five to six interviews were conducted in each organisation, first at the headquarters and then at the program level in Chad. Interviews at the headquarters were conducted by the main researcher and a research assistant, who was not informed about our framework at the time of interview. Post holders such as a CEO, supply 
chain managers, logistics managers, program managers, and logistics assistants were interviewed between October and December 2011, following a structured interview guide. The average length of the interview was 58 minutes. Interviews at the program level in Chad were conducted by the main researcher in the country, following the same structured interview guide. All interview notes were sent to respondents for validation. The list of interviews in Appendix provides the organisation, function and level (headquarters or field) of each interviewee.

\subsection{Data Analysis}

The data analysis was conducted by the main researcher and a research assistant. We applied an analytic induction process (Znaniecki 1934), that consists of first formulating tentative propositions based on literature and an early comprehension of the topic, then collecting data and refining these propositions through an analysis of all data until - in theory 'universal' causal relationships are distilled. This approach is operationalised in our propositions, which were tentatively defined based on our research framework, and then tested by comparing them with all case study data (primary and secondary) through qualitative content analysis. Qualitative content analysis provides a structured procedure for systematically filtering conceptual arguments from the abundance of case study data (Duriau, Reger, and Pfarrer 2007).

Only propositions which find supporting evidence in all case organisations are (tentatively) accepted. Where proposition and data at hand do not match, the propositions are reformulated and their context of application modified. Due to resource constraints (basically regarding fixed-term research funding), we had to interrupt the analytic induction process at this point. Follow-up research may collect new case study data for further refining research propositions and their area of application. 


\subsection{Quality}

In order to generate valid and reliable findings, we followed a structured and replicable research design which ensures high levels of methodological rigor. Table 2 presents the different actions taken to ensure the high quality of our research, based on recommendations from the literature (Barratt, Choi, and Li 2011; Eisenhardt 1989; Stuart et al. 2002; Voss, Tsikriktsis, and Frohlich 2002; Yin 2009).

Table 2. Actions taken to increase the quality of the research (based on recommendations from Eisenhardt, 1989, Voss et al., 2002, Yin, 2009).

\begin{tabular}{|c|c|}
\hline Criteria & Actions \\
\hline Internal validity & $\begin{array}{l}\text { - Develop propositions on the basis of a research framework backed by theory from the } \\
\text { streams of sustainable SCM and humanitarian SCM } \\
\text { - Investigate convergence and divergence between propositions and empirically } \\
\text { observed patterns by structured content analysis } \\
\text { - Link empirical results back to literature thus defining theoretical contribution } \\
\text { - Present and discuss early versions of the paper at academic conferences }\end{array}$ \\
\hline External validity & $\begin{array}{l}\text { - Collect data at headquarters, from potentially } 146 \text { programs worldwide } \\
\text { - Apply (polar-type) theoretical sampling mechanism along theoretical categories, } \\
\text { namely age of the program and size of the organisation } \\
\text { - Collect interview data until theoretical saturation is reached } \\
\text { - Extend conceptual generality by de-contextualising findings through theoretical } \\
\text { abstraction }\end{array}$ \\
\hline Construct validity & $\begin{array}{l}\text { - Triangulate between multiple sources of evidence (including primary and secondary } \\
\text { data) } \\
\text { - Use structured interview protocol } \\
\text { - Maintain a clear chain of evidence by iteratively comparing data with theoretical } \\
\text { constructs and their hypothesised inter-relationships (RP1-RP4) }\end{array}$ \\
\hline Reliability & $\begin{array}{l}\text { - Conduct data collection and analysis with two researchers } \\
\text { - Validate interview notes by respondents } \\
\text { - Use structured interview protocol also containing fixed-choice answers }\end{array}$ \\
\hline
\end{tabular}

\section{Results}

In this section, the propositions (RP1-RP4) will be tested in a cross-case analysis, following the analytic induction process described in the previous section. Most of the evidence provided is related to our focus country, Chad. Some relates to programs in other countries 
(e.g., Ethiopia as another developing country in the rehabilitation phase of a complex disaster).

\subsection{Research Proposition RP1}

Organisation B, which is a well-established relief organisation with 30 years of experience in Chad, has developed a strong capability to adapt to the local socio-economic context, as demonstrated by their local procurement policy. The organisation gives preference to local purchasing rather than international supply whenever possible because of its positive impact on the economic development of the affected country's local economy, as well as its better fit with cultural and regional requirements. This local purchasing preference is operationalised in a specific policy (relief organisation's enablers). Different long-term requirements of the population can be identified in this context. The quality and availability of the relief goods is the major need of the beneficiaries, but the whole population's long-term interest is that local industry (i.e., companies manufacturing and distributing these goods in the country) is not harmed by the delivery of internationally sourced free relief supplies. The existence of a strong local supplier base with enough capacity to deliver to the relief organisation is one socio-economic contingency factor which determines if local sourcing is a feasible option, and whether it leads to inflationary pressure on prices or not.

The data shows that the relief organisation follows a specific procedure before adapting its supply chain design and procuring items locally. It first checks the availability of locally produced goods, both in terms of quantity and quality. If the availability is guaranteed, the cost of the goods as well as the potential positive (strengthening of local industry) and negative impacts (inflationary pressure on prices) of local purchasing are assessed. If these evaluations indicate an overall positive impact, the organisation decides to procure the items locally. 
On the contrary, Organisation A, which only started its program in Chad some months before the interview, faced an issue with the importation process of their equipment. Due to limited resources (enablers), they imported an old truck from Europe. Due to their limited knowledge of governmental contingency factors, they were unaware that the government of Chad did not allow the importation of vehicles older than 10 years. When crossing the border, they were not allowed to enter the country with this truck, which led to several weeks of delays and so impacted the program they were running. This case demonstrates that a low level of enablers limits a relief organisation's capacity to find a supply chain design that accommodates the population's long-term requirements and contingency factors. Table 3 shows exemplary statements of respondents from the remaining Organisation C and D that support the validity of RP1.

Table 3. Additional statements from case organisations supporting RP1.

\begin{tabular}{l|l} 
Organisation & Statements \\
\hline Organisation C & $\begin{array}{l}\text { In most countries (17 out of 20) we have a 'pre-clearance' process, for which we prepare } \\
\text { all required documents for the custom clearance before the goods arrive at the customs. } \\
\text { Once everything is ready, we bring the goods to custom, and as all the paperwork is } \\
\text { already done, we are able to import very quickly. Sometimes it takes no time at all; we } \\
\text { can even go with our truck directly on the tarmac and load the goods ourselves. (Head of } \\
\text { Supply, HQ) } \\
\text { Organisation D }\end{array}$ \\
$\begin{array}{l}\text { Our rule for non-medical items is to try to purchase them locally. We do this for } \\
\text { furniture, computers, office consumables, etc. (Africa Desk Officer, HQ) }\end{array}$
\end{tabular}

\subsection{Research Proposition RP2}

Organisation's C policy is that each medicine it prescribes has to fulfil the same quality requirements as for patients in Europe (long-term requirements of the population). This is important since most developing countries do not have regulations in place concerning medicines. Whenever locally manufactured medicines are available or imposed by the government, the relief organisation has a network of pharmacists for analysing the quality of medicines. If the quality fits the requirements, the medicines can be used by the organisation in this country, otherwise medicines are imported. These sourcing requirements and 
procedures as well as the organisation's network of pharmacists are part of the relief organisation's enablers.

In 2011, the Ethiopian Food, Medicine and Health Care Administration and Control Authority (FMHACA) changed its rules and allowed only registered medicines to be used in the country. Such regulation is common in most developed countries. However, the list of medicines registered in Ethiopia was limited to those locally produced or distributed. This regulation can be seen as a governmental contingency factor.

Faced with this contingency factor, the relief organisation used its enablers (pharmacists) to test the locally available medicines. These medicines did not satisfy the requirements defined by the organisation, and so it decided not to use these substandard medicines. By the end of 2011, following intense negotiation with the Ethiopian government, the FMHACA agreed to adapt the regulation and allowed the importation of medicines if a particular substance is not available on the list of registered medicines and was prequalified by the World Health Organization, or registered in the USA or in Europe. This example shows that when the long-term requirement of the population is comprehensively taken into account, the relief organisation has to develop ingenious ways to leverage its enablers (i.e., pharmacists, negotiation) in order to find a supply chain design that accommodates these requirements within governmental contingency factors.

An example from Organisation A also supports this proposition. When conducting the assessment for their operation in the north of Chad, the organisation noticed a poor water supply in the small village where they planned to work. The water from the only well was not drinkable and was only available in limited quantities anyway. The simplest option would have been to bring water filters and use the water from the well for their staff. This option, however, would have increased the risk of drying up the well and so negatively impacting the population of the area. An alternative option would have been to use bottled water and bring 
water for general needs in tanks. Instead, realising the long-term needs of the local population, the organisation decided to use part of their infrastructure budget to drill a new, deeper well in the village where it was operating. This ingenious use of the organisation's resources (enablers) is an example of a supply chain design that takes into account the population's long-term requirements, and thus leads to sustainable performance. Table 4 provides exemplary statements of respondents from Organisation B and D that support this proposition.

Table 4. Additional statements from case organisations supporting RP2.

\begin{tabular}{l|l} 
Organisation & Statements \\
\hline Organisation B & $\begin{array}{l}\text { One of our programs helps people to buy supplies locally at reasonable } \\
\text { conditions, instead of just giving them for free. (Head of Sector Logistics, Central } \\
\text { and Southern Africa, HQ) } \\
\text { Organisation D }\end{array}$ \\
$\begin{array}{l}\text { We maintain good relations with the key persons in the different customs offices. If } \\
\text { I go there, I say good morning to the person in charge of the office, ask how there } \\
\text { are doing, etc. If these persons know you and have a good opinion of you, it } \\
\text { facilitates a lot the custom clearance process. (Logistics Assistant, Chad) }\end{array}$
\end{tabular}

\subsection{Research Proposition RP3}

In a country such as Chad, where the government is generally cooperative (despite imposing restrictions on relief organisations), Organisations B, C and D were able to negotiate a preclearance agreement with the government. This allowed these organisations to accommodate governmental contingency factors by developing a supply chain design that allows for the importing of supplies without having to wait for long customs clearance processes, and thus better satisfies the population's long-term requirements.

The problem experienced by Organisation A with the customs clearance of its truck (see above) was finally solved because the Organisation was able to leverage its relationships with one Ministry (enabler) in order to get the required exemptions. The cooperative behaviour of the government of Chad finally made it possible for the organisation to accommodate this governmental contingency factor and so import the truck. 
In the case of Ethiopia, where the government was less cooperative, Organisation D faced several issues regarding long importation processes as well as travel limitations. The organisation negotiated and adapted to governmental requirements for years, but in 2011 it decided to withdraw from the country, partially because of the lack of cooperation from the government. With a non-cooperative government, the organisation was not able to identify a supply chain design that accommodated the governmental contingency factors, despite having leveraged its enablers. By leaving the country, the population's long-term requirements could obviously not be met. Table 5 provides additional exemplary supporting statements of respondents from Organisation B and C.

Table 5. Additional statements from case organisations supporting RP3.

\begin{tabular}{l|l} 
Organisation & Statements \\
\hline Organisation B & $\begin{array}{l}\text { When a country declares a 'state of emergency', this is very much facilitating the import } \\
\text { process, as it allows you to send supplies quickly and easily, without going through } \\
\text { standard custom clearance processes. (Head of Sector Logistics, East and Central Asia, } \\
\text { HQ) } \\
\text { Motivation of government to impose barriers: The international presence of NGOs and } \\
\text { international organisations is seen as a support to the local economy, and a financial } \\
\text { contribution for the government. (Deputy Head of Delegation, Chad) } \\
\text { When we are in an emergency setting, it can be problematic if there are no previously } \\
\text { established relationships with authorities. In such case, it can easily take two to three } \\
\text { weeks until the goods are through customs. But most of the time, If you have good } \\
\text { relationships with the Ministry of Health, they really help you to clear the road } \\
\text { immediately. (Logistics Director, HQ) }\end{array}$
\end{tabular}

\subsection{Research Proposition RP4}

The case of Organisation C importing medicines in Ethiopia demonstrates that higher social performance can be achieved by a supply chain design that accommodates the population's long-term requirements (quality medicines) and governmental contingency factors (push for local procurement). The pre-clearance process developed by Organisations B, C and D, and the well that Organisation A dug in the north of Chad, provide evidence that higher social performance can be achieved through a supply chain design that better accommodates the 
population's long-term requirements and contingency factors.

The local procurement procedure developed by Organisation B demonstrates that a supply chain design that accommodates the population's long-term requirements and socioeconomic contingency factors leads to higher economic performance.

However, in our case studies we were not able to identify any hint that a supply chain design accommodating the population's long-term requirements and contingency factors led to higher ecological performance, so we had to modify this proposition. Based on our data, humanitarian supply chains achieve sustainability of performance only on a shortened double bottom line comprising the social and economic sustainability dimension instead of a comprehensive TBL.

\section{Discussion}

Observations from our case organisations all back proposition RP1. We therefore conclude that the more enablers a relief organisation has, the greater is its capacity to establish a supply chain design that accommodates the population's long-term requirements and contingency factors. A relief organisation lacking the required enablers (Organisation A) will face difficulties adapting to contingency factors, whereas an organisation with well-developed enablers (Organisation B) will have the ability to invest in the implementation of a supply chain design that accommodates these factors. An organisation with a high level of enablers will, for example, have the capability to conduct an assessment of the inflationary pressure that local procurement may have on prices (Garg et al. 2013; Barrett et al. 2009). Such an organisation will also have higher resources to invest into assessing the capabilities of local suppliers. Working with local partners who are knowledgeable about the requirements of the population will then help the relief organisation make better sourcing decisions (McLachlin, Larson, and Khan 2009). 
Data from all our case organisations supports proposition RP2. We therefore conclude that comprehensively taking into account the population's long-term requirements requires ingenious ways of leveraging enablers to accommodate these requirements and contingency factors. By refusing to use medicines which were considered safe by the government, Organisation $\mathrm{C}$ took the long-term needs of the population comprehensively into account. However, hard negotiations with the government were required until the organisation found a way to accommodate these contingency factors. Considering the needs of the population as well as the potential negative effect of humanitarian interventions on these populations, Organisation A had to think outside of the box and use its resources for drilling a new well, an activity totally outside its regular field of activities. Organisation D had to invest time in building relationships and negotiating agreements with the government, which is in line with suggestions from previous research (See e.g., Kunz, Reiner, and Gold 2014; Kovács and Tatham 2009), but is not the core activity of a relief organisation.

Based on our case organisations, proposition RP3 is empirically corroborated. The examples of Organisations B, C and D in Chad demonstrate that when a government is cooperative, it is easier for relief organisations to leverage their enablers to establish a supply chain design that accommodates contingency factors and the population's long-term requirements. The example of Organisation A shows that this cooperation allows a relief organisation to better accommodate governmental contingency factors. In countries where the government has a lower level of cooperation, such as Ethiopia, it is much more difficult for relief organisations to establish a supply chain design that accommodates the population's long-term requirements and contingency factors, as demonstrated by the difficulties for Organisation $\mathrm{C}$ in importing medicines, or by the impossibility for Organisation D to operate in this country due to travel and import restrictions. 
Based on our case organisations, we were not able to support comprehensively proposition RP4 because we could not identify any examples where a relief organisation used its enablers to establish a supply chain design that lead to higher environmental performance. This absence of focus of relief organisations on environmental performance reflects the core mission of our case organisations, which is clearly in the field of social betterment for the disaster-struck population. In the context of developing countries in the rehabilitation phase of a complex disaster, social betterment is intimately linked to economic development if it serves broad parts of the population. Nonetheless, the absence of consideration of environmental outcome is surprising, as climate change is 'considered as being the root cause of natural disasters such as flooding and hurricanes' (Halldórsson and Kovács 2010, p.7). However, our cases demonstrate that higher economic and social performances are achieved by supply chain designs that better accommodate the population's long-term requirements and contingency factors. The limitation of sustainable performance to only social and economic factors while largely neglecting environmental aspects is in line with recent findings of Haavisto and Kovács (2014) and Abrahams (2014). Gold et al. (2013) found similar results regarding sustainability performance of supply chains operating at the so-called Base of the Pyramid (i.e., in resource-poor developing country contexts). Following our analytic induction process, we modify RP4 in such a way that it reflects the findings from our case studies, by removing the ecological dimension of performance:

RP4.1: The more effective supply chain design accommodates the relief organisation's enablers with the population's long-term requirements under consideration of contingency factors, the higher is the double-bottom line sustainability performance. Thereby, double-bottom line sustainability performance is conceived as value created on the economic and social dimension.

Our integrated framework of sustainable humanitarian SCM has predominantly taken a TBL approach. We focused on this concept because it is commonly used in SCM research. We 
acknowledge that sustainability in humanitarian operations may be conceptualized in other ways, for example through concepts such as proper exit strategies, aid effectiveness, or disaster risk reduction. These interesting concepts from the fields of disaster management and development studies are however beyond the scope of this paper.

\section{Conclusion}

The findings of this research have various implications for theory and practice. In the theoretical dimension, our paper is the first attempt to develop a framework for sustainable humanitarian SCM by merging a model of sustainable SCM with a model of humanitarian SCM. By bringing these two relatively new fields of research together, we answer the call for more research on the sustainability of humanitarian SCM. More specifically, our framework lays a first foundation for analysing disaster relief supply chain operations against multidimensional sustainability performance that explicitly considers the long-term requirements of the affected and adjacent population as well as additional contingency factor. The framework we developed based on the literature on sustainable SCM and humanitarian SCM needs to be further validated through case study or survey based approaches. It can then be used by researchers combining these two areas. It may, for example, provide a rationale for studying the success or failure of different relief supply chain designs in the rehabilitation phase, and for differentiating between short-term and long-term performance assessments.

Our paper also has several implications for practice. The framework we developed provides an instrument for relief organisation managers for achieving sustainable performance in the rehabilitation phase, for example by facilitating long-term development of capabilities of affected people and thus strengthening resilience of communities. It also provides managers with an understanding of how contingency factors affect the supply chain, and how they can best be handled. The examples from our case studies encourage relief organisations to be flexible and proactive in adapting their supply chain design to contingency factors, and 
so to reach sustainable performance. Based on our findings, we recommend relief organisations develop a better understanding of the motivations of governments to impose restrictions, and proactively try to engage with government officials with the aim of finding win-win solutions to specific problems. We also encourage relief organisations to seek a better understanding of the population's long-term requirements, in order to avoid hurting the non-affected population when helping victims of a disaster. Free provision of imported food over long periods should, for example, be avoided in order to not harm the economy of the affected country. We also recommend relief organisations increasingly integrate the environmental dimension of sustainability into their supply chain, especially in the rehabilitation phase.

Another practical implication of our research is that governments are encouraged to develop a better understanding of relief organisations' processes, and in particular to identify how specific regulations can hamper the sustainable performance of humanitarian SCM in the long run. Governments should, for example, think about innovative solutions enabling easier importation processes for relief organisations, without compromising safety of the population. The preclearance process described earlier, or the recognition of an international medicine accreditation body, are good examples of such innovative approaches.

Finally, donors are encouraged to consider the sustainability of the rehabilitation phase of a disaster when developing their procurement policies. For example, requiring relief organisations to procure supplies in the donor's home country is not sustainable for the beneficiary country and should be avoided. Similarly, when assessing relief organisation proposals, donors should look specifically at the organisation's ability to implement sustainable supply chain strategies for addressing local contingency factors.

The main limitation of this paper lies in the limited empirical evidence for our framework of sustainable humanitarian SCM. We tested each of our research propositions 
against the data from our four case organisations, but the applicability and validity of our framework still needs to be corroborated by follow-up qualitative and quantitative empirical research, including the testing of our propositions regarding the interrelation of various constructs as well as further specification and consolidation of single constructs. In this way, humanitarian SCM may gradually develop towards a contingent management theory and practice that comprehensively accounts for sustainable performance. A limitation of our framework is that it does not include donors, who are important stakeholders for relief organizations. Further research could analyse how the different funding structures of relief organizations impact sustainable humanitarian supply chain management. Further research could also analyse the sustainability of new practices in relief aid, such as cash and voucher programs replacing food aid distribution.

\section{References}

Abbasi, Maisam, and Fredrik Nilsson. 2012. "Themes and challenges in making supply chains environmentally sustainable." Supply Chain Management: An International Journal 17 (5):517-30.

Abrahams, Daniel. 2014. "The barriers to environmental sustainability in post-disaster settings: a case study of transitional shelter implementation in Haiti." Disasters 38 (s1):S25-S49.

Altay, Nezih, and Walter G. Green. 2006. "OR/MS research in disaster operations management." European Journal of Operational Research 175 (1):475-93. doi: 10.1016/j.ejor.2005.05.016.

Balcik, Burcu, and Benita M. Beamon. 2008. "Facility location in humanitarian relief." International Journal of Logistics: Research \& Applications 11 (2):101-21. doi: 10.1080/13675560701561789.

Balcik, Burcu, Benita M. Beamon, Caroline C. Krejci, Kyle M. Muramatsu, and Magaly Ramirez. 2010. "Coordination in humanitarian relief chains: Practices, challenges and opportunities." International Journal of Production Economics 126 (1):22-34. doi: 10.1016/j.ijpe.2009.09.008.

Barratt, Mark, Thomas Y. Choi, and Mei Li. 2011. "Qualitative case studies in operations management: Trends, research outcomes, and future research implications." Journal of Operations Management 29 (4):329-42. doi: http://dx.doi.org/10.1016/j.jom.2010.06.002.

Barrett, Christopher B, Robert Bell, Erin C Lentz, and Daniel G Maxwell. 2009. "Market information and food insecurity response analysis." Food Security 1 (2):151-68.

Beamon, Benita M., and Stephen A. Kotleba. 2006. "Inventory modelling for complex emergencies in humanitarian relief operations." International Journal of Logistics: Research \& Applications 9 (1):1-18. doi: 10.1080/13675560500453667. 
Besiou, M., O. Stapleton, and L.N. Van Wassenhove. 2011. "System dynamics for humanitarian operations." Journal of Humanitarian Logistics and Supply Chain Management 1 (1):78-103.

Brundtland, Gro Harlem. 1987. Our Common Future. Brussels, Belgium: United Nations World Commission on Environment and Development.

Cantor, David E, Paula C Morrow, James C McElroy, and Frank Montabon. 2013. "The role of individual and organizational factors in promoting firm environmental practices." International Journal of Physical Distribution \& Logistics Management 43 (5/6):407-27.

Christoplos, Ian. 2006. "Links between relief, rehabilitation and development in the tsunami response." In. London, UK: Tsunami Evaluation Coalition.

CIA. "World Factbook." Accessed 29.07.2014. https://www.cia.gov/library/publications/the-worldfactbook/geos/cd.html.

Daghfous, Abdelkader. 2007. "Absorptive capacity and innovative enterprise systems: a two-level framework." International Journal of Innovation and Learning 4 (1):60-73.

Day, Jamison M., Steven A. Melnyk, Paul D. Larson, Edward W. Davis, and D. Clay Whybark. 2012. "Humanitarian and disaster relief supply chains: A matter of life and death." Journal of Supply Chain Management 48 (2):21-36. doi: 10.1111/j.1745-493X.2012.03267.x.

Duriau, Vincent J., Rhonda K. Reger, and Michael D. Pfarrer. 2007. "A content analysis of the content analysis literature in organization studies: Research themes, data sources, and methodological refinements." Organizational Research Methods 10 (1):5-34.

Dyllick, Thomas, and Kai Hockerts. 2002. "Beyond the business case for corporate sustainability." Business Strategy and the Environment 11 (2):130-41.

Eisenhardt, Kathleen M. 1989. "Building theories from case study research." Academy of Management Review 14 (4):532-50.

Flynn, Barbara B., Baofeng Huo, and Xiande Zhao. 2010. "The impact of supply chain integration on performance: A contingency and configuration approach." Journal of Operations Management 28 (1):58-71. doi: http://dx.doi.org/10.1016/j.jom.2009.06.001.

Gaillard, Jean-Christophe. 2007. "Resilience of traditional societies in facing natural hazards." Disaster Prevention and Management 16 (4):522-44.

Garg, Teevrat, Christopher B. Barrett, Miguel I. Gómez, Erin C. Lentz, and William J. Violette. 2013. "Market Prices and Food Aid Local and Regional Procurement and Distribution: A Multi-Country Analysis." World Development 49 (0):19-29. doi: http://dx.doi.org/10.1016/j.worlddev.2013.01.018.

Gimenez, Cristina, Vicenta Sierra, and Juan Rodon. 2012. "Sustainable operations: Their impact on the triple bottom line." International Journal of Production Economics 140 (1):149-59.

Gimenez, Cristina, and Elcio M Tachizawa. 2012. "Extending sustainability to suppliers: a systematic literature review." Supply Chain Management: An International Journal 17 (5):531-43.

Gold, Stefan, Rüdiger Hahn, and Stefan Seuring. 2013. "Sustainable supply chain management in "Base of the Pyramid" food projects: A path to triple bottom line approaches for multinationals?" International Business Review 22 (5):748-99. doi: http://dx.doi.org/10.1016/j.ibusrev.2012.12.006. 
Gold, Stefan, Stefan Seuring, and Philip Beske. 2010. "Sustainable supply chain management and inter-organizational resources: A literature review." Corporate Social Responsibility and Environmental Management 17 (4):230-45.

Haavisto, Ira, and Gyöngyi Kovács. 2014. "Perspectives on sustainability in humanitarian supply chains." Disaster Prevention and Management 23 (5):610-31. doi: 10.1108/dpm-10-2013-0192.

Hahn, Rüdiger, and Stefan Gold. 2014. "Resources and governance in "base of the pyramid"partnerships: Assessing collaborations between businesses and non-business actors." Journal of Business Research 67 (7):1321-33.

Halldórsson, Árni, and Gyöngyi Kovács. 2010. "The sustainable agenda and energy efficiency: Logistics solutions and supply chains in times of climate change." International Journal of Physical Distribution \& Logistics Management 40 (1):5-13. doi: 10.1108/09600031011018019.

Han, Guanghua, and Ming Dong. 2015. "Trust-embedded coordination in supply chain information sharing." International journal of production research 53 (18):5624-39.

Heaslip, Graham, and Elizabeth Barber. 2014. "Using the military in disaster relief: systemising challenges and opportunities." Journal of Humanitarian Logistics and Supply Chain Management 4 (1):60-81.

Herlin, Heidi, and Ala Pazirandeh. 2012. "Nonprofit organizations shaping the market of supplies." International Journal of Production Economics 139 (2):411-21. doi: 10.1016/j.ijpe.2011.04.003.

Holguín-Veras, José, Miguel Jaller, Luk N. Van Wassenhove, Noel Pérez, and Tricia Wachtendorf. 2012. "On the unique features of post-disaster humanitarian logistics." Journal of Operations Management 30 (7-8):494-506. doi: 10.1016/j.jom.2012.08.003.

Huang, Ming-Chang, Ghi-Feng Yen, and Tzu-Chuan Liu. 2014. "Reexamining supply chain integration and the supplier's performance relationships under uncertainty." Supply Chain Management: An International Journal 19 (1):64-78.

IMF. 2014. "World Economic Outlook April 2014." In. Washington, DC: IMF.

Jahre, Marianne, and Karen M. Spens. 2007. Buy global or go local-that's the question. Paper presented at the 1st Conference of Humanitarian Logistics, CCHLI, UK, November 2007.

Kovács, Gyöngi, and Karen M. Spens. 2011. Relief Supply Chain for Disasters: Humanitarian, Aid and Emergency Logistics. Edited by Gyöngi Kovács. Hershey, PA: Business Science Reference.

Kovács, Gyöngyi, Aristides Matopoulos, and Odran Hayes. 2010. "A community-based approach to supply chain design." International Journal of Logistics: Research and Applications 13 (5):411-22.

Kovács, Gyöngyi, and Karen M. Spens. 2007. "Humanitarian logistics in disaster relief operations." International Journal of Physical Distribution \& Logistics Management 37 (2):99-114. doi: 10.1108/09600030710734820.

Kovács, Gyöngyi, and Peter Tatham. 2009. "Responding to disruptions in the supply network - From dormant to action." Journal of Business Logistics 30 (2):215-29.

Kunz, Nathan, and Gerald Reiner. 2012. "A meta-analysis of humanitarian logistics research." Journal of Humanitarian Logistics and Supply Chain Management 2 (2):116-47. doi: $10.1108 / 20426741211260723$. 
Kunz, Nathan, Gerald Reiner, and Stefan Gold. 2014. "Investing in disaster management capabilities versus pre-positioning inventory: A new approach to disaster preparedness." International Journal of Production Economics 157 (November 2014):261-72. doi:

http://dx.doi.org/10.1016/j.ijpe.2013.11.002.

Lai, Ka-Man, Claudia Ramirez, Weilong Liu, Darina Kirilova, David Vick, Joe Mari, Rachel Smith, Ho-Yin Lam, Afshin Ostovari, and Akifumi Shibakawa. 2015. "Bridging the sanitation gap between disaster relief and development." Disasters 39 (4):648-64.

Lawrence, Paul R, and Jay W Lorsch. 1967. Organization and Environment: Managing Differentiation and Integration. Cambridge, MA: Harvard University Press.

Leiras, Adriana, Irineu de Brito, Eduardo Queiroz Peres, Tábata Rejane Rejane Bertazzo, and Hugo T. Y. Yoshizaki. 2014. "Literature review of humanitarian logistics research: trends and challenges." Journal of Humanitarian Logistics and Supply Chain Management 4 (1):95 - 130.

Lentz, Erin C., Simone Passarelli, and Christopher B. Barrett. 2013. "The Timeliness and CostEffectiveness of the Local and Regional Procurement of Food Aid." World Development 49 (September 2013):9-18. doi: http://dx.doi.org/10.1016/j.worlddev.2013.01.017.

Long, Douglas C., and Donald F. Wood. 1995. "The logistics of famine relief." Journal of Business Logistics 16 (1):213-29.

Maon, François, Adam Lindgreen, and Joëlle Vanhamme. 2009. "Developing supply chains in disaster relief operations through cross-sector socially oriented collaborations: a theoretical model." Supply Chain Management: An International Journal 14 (2):149-64.

Maxwell, Daniel. 2007. "Global factors shaping the future of food aid: the implications for WFP." Disasters 31 (s1):S25-S39.

McLachlin, R., P.D. Larson, and S. Khan. 2009. "Not-for-profit supply chains in interrupted environments: The case of a faith-based humanitarian relief organisation." Management Research News 32 (11):1050-64.

Oloruntoba, Richard, and Richard Gray. 2006. "Humanitarian aid: an agile supply chain?" Supply Chain Management: An International Journal 11 (2):115-20.

Pagell, Mark, and Zhaohui Wu. 2009. "Building a more complete theory of sustainable supply chain management using case studies of 10 exemplars." Journal of Supply Chain Management 45 (2):3756. doi: 10.1111/j.1745-493X.2009.03162.x.

Pazirandeh, Ala. 2011. "Sourcing in global health supply chains for developing countries." International Journal of Physical Distribution \& Logistics Management 41 (4):364-84.

Perry, Marcia. 2007. "Natural disaster management planning: A study of logistics managers responding to the tsunami." International Journal of Physical Distribution \& Logistics Management 37 (5):409-33. doi: 10.1108/09600030710758455.

Pettit, Stephen, and Anthony Beresford. 2005. "Emergency relief logistics: an evaluation of military, non-military and composite response models." International Journal of Logistics: Research \& Applications 8 (4):313-31. doi: 10.1080/13675560500407325.

Pettit, Stephen, and Anthony Beresford. 2009. "Critical success factors in the context of humanitarian aid supply chains." International Journal of Physical Distribution \& Logistics Management 39 (6):450-68. doi: 10.1108/09600030910985811. 
Ramet, Valerie. 2012. "Linking relief, rehabilitation and development: Towards more effective aid " In. Brussels, BE: Directorate-General for External Policies of the European Union

Rodon, Juan, Josep F. Maria Serrano, and Cristina Gimenez. 2012. "Managing cultural conflicts for effective humanitarian aid." International Journal of Production Economics 139 (2):366-76. doi: http://dx.doi.org/10.1016/j.ijpe.2011.08.029.

Schrettle, Stefan, Andreas Hinz, Maike Scherrer-Rathje, and Thomas Friedli. 2014. "Turning sustainability into action: Explaining firms' sustainability efforts and their impact on firm performance." International Journal of Production Economics 147 (PA):73-84.

Schultz, Jessica, and Tina Søreide. 2008. "Corruption in emergency procurement." Disasters 32 (4):516-36.

Seekins, Donald M. 2009. "State, society and natural disaster: Cyclone Nargis in Myanmar (Burma)." Asian Journal of Social Science 37 (5):717-37. doi: 10.1163/156848409x12474536440500.

Seuring, Stefan, and Martin Müller. 2008. "From a literature review to a conceptual framework for sustainable supply chain management." Journal of Cleaner Production 16 (15):1699-710. doi: http://dx.doi.org/10.1016/j.jclepro.2008.04.020.

Sheppard, Allan, Peter Tatham, Ron Fisher, and Rod Gapp. 2013. "Humanitarian logistics: Enhancing the engagement of local populations." Journal of Humanitarian Logistics and Supply Chain Management 3 (1):22-36.

Silvestre, Bruno S. 2015. "Sustainable Supply Chain Management in Emerging Economies: Environmental Turbulence, Institutional Voids and Sustainability Trajectories." International Journal of Production Economics 167 (September 2015):156-69.

Slack, N., and M. Lewis. 2002. Operations Strategy. Essex, UK: Pearson.

Sousa, Rui, and Chris Voss. 2008. "Contingency research in operations management practices." Journal of Operations Management 26 (6):697-713. doi:

http://dx.doi.org/10.1016/j.jom.2008.06.001.

Starr, Martin K., and Luk N. Van Wassenhove. 2014. "Introduction to the Special Issue on Humanitarian Operations and Crisis Management." Production and Operations Management 23 (6):925-37. doi: 10.1111/poms.12227.

Stuart, Ian, David McCutcheon, Robert Handfield, Ron McLachlin, and Danny Samson. 2002. "Effective case research in operations management: a process perspective." Journal of Operations Management 20 (5):419-33.

Thomas, Anisya S., and Laura R. Kopczak. 2005. From Logistics to Supply Chain Management: The Path Forward in the Humanitarian Sector, White Paper. San Francisco, CA: Fritz Institute.

Vachon, Stephan, and Robert D. Klassen. 2008. "Environmental management and manufacturing performance: The role of collaboration in the supply chain." International Journal of Production Economics 111 (2):299-315.

van Hoof, Bart, and Marcus Thiell. 2014. "Collaboration capacity for sustainable supply chain management: small and medium-sized enterprises in Mexico." Journal of Cleaner Production 67:239-48. doi: http://dx.doi.org/10.1016/j.jclepro.2013.12.030.

Van Wassenhove, Luk N. 2006. "Blackett Memorial Lecture Humanitarian aid logistics: Supply chain management in high gear." Journal of the Operational Research Society 57 (5):475-89. 
Van Wassenhove, Luk N., and Alfonso J. Pedraza Martinez. 2012. "Using OR to adapt supply chain management best practices to humanitarian logistics." International Transactions in Operational Research 19 (1-2):307-22. doi: 10.1111/j.1475-3995.2011.00792.x.

Voss, Chris, Nikos Tsikriktsis, and Mark Frohlich. 2002. "Case research in operations management." International Journal of Operations and Production Management 22 (2):195-219.

Wagner, Stephan M., and Christoph Bode. 2008. "An empirical examination of supply chain performance along several dimensions of risk." Journal of Business Logistics 29 (1):307-25. doi: 10.1002/j.2158-1592.2008.tb00081.x.

Wu, Zhaohui, and Mark Pagell. 2011. "Balancing priorities: Decision-making in sustainable supply chain management." Journal of Operations Management 29 (6):577-90.

Yawar, Sadaat Ali, and Stefan Seuring. 2015. "Management of Social Issues in Supply Chains: A Literature Review Exploring Social Issues, Actions and Performance Outcomes." Journal of Business Ethics:1-23. doi: 10.1007/s10551-015-2719-9.

Yin, Robert K. 2009. Case Study Research: Design and Methods. Thousand Oaks, CA: Sage.

Znaniecki, Florian. 1934. The Method of Sociology. New York, NY: Farrar \& Rinehart. 
Appendix: List of interviews

\begin{tabular}{c|l|c|c} 
Organisation & Position & Level & Location of interview \\
\hline A & Administrative Director & HQ & Tavannes, Switzerland \\
A & CEO & HQ & Tavannes, Switzerland \\
A & Institutional Advisor & HQ & Tavannes, Switzerland \\
A & Supply Chain Manager & HQ & Tavannes, Switzerland \\
A & Program Manager & Field & N'Djamena, Chad \\
A & Technical Field Manager & Field & N'Djamena, Chad \\
\hline B & Head of Sector Logistics, Central and Southern Africa & HQ & Geneva, Switzerland \\
\hline B & Head of Sector Logistics, East and Central Asia & HQ & Geneva, Switzerland \\
B & Logistics Assistant Import-Export & Field & N'Djamena, Chad \\
\hline B & Deputy Head of Delegation & Field & N'Djamena, Chad \\
B & Logistics Manager & Field & Abéché, Chad* \\
\hline C & Coordinator Procurement Unit & HQ & Amsterdam, Netherlands* \\
\hline C & Head of Operational Logistics & HQ & Geneva, Switzerland \\
C & Head of Supply & HQ & Geneva, Switzerland \\
C & Logistics Director & HQ & Geneva, Switzerland \\
C & Logistics Coordinator & Field & N'Djamena, Chad \\
C & Finance Coordinator & Field & N'Djamena, Chad \\
\hline D & Africa Desk Officer & HQ & Paris, France \\
D & Head of Logistics Services & HQ & Paris, France \\
D & General Coordinator & Field & N'Djamena, Chad \\
D & Logistician & Field & N'Djamena, Chad \\
D & Logistics Assistant & Field & N'Djamena, Chad \\
\hline
\end{tabular}

*interview conducted by phone

Funding: This work was supported by the Swiss National Science Foundation [grant number 143578] and the University of Neuchâtel. 